\title{
Clinical evaluation of potential usefulness of serum lactate dehydrogenase (LDH) in 2019 novel coronavirus (COVID-19) pneumonia
}

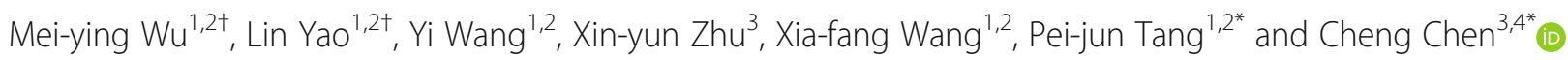

\begin{abstract}
Background: There was much evidence suggesting that the serum lactate dehydrogenase (LDH) levels reflect the extent of various pathophysiological processes. However, the current information about dynamic change of LDH in COVID-19 pneumonia has not been well investigated.

Methods: Study was performed in 87 cases confirmed by COVID-19 infection. The serum LDH levels were determined at diagnosis and follow-up visits. The evaluation of clinical response to therapy was based on chest CT scan. We selected the value of LDH around the data of chest CT scan $(-1 \sim+1$ day).

Results: At diagnosis, significant differences in LDH levels were found between non-severe and severe group $(P<$ 0.05). It was demonstrated that increase or decrease of $L D H$ was indicative of radiographic progress or improvement $(P<0.05)$. The time to $\mathrm{LDH}$ normalization $(5.67 \pm 0.55$, days) was positively correlated with the time to radiographic absorption $(5.57 \pm 0.65$ days, $r=0.53, P<0.05)$. Applying the cut-off value of the increase in LDH has good specificity to predict disease progression.

Conclusions: Serum LDH was validated for its potential usefulness as markers for evaluating clinical severity and monitoring treatment response in COVID-19 pneumonia.
\end{abstract}

Keywords: COVID-19, Pneumonia, LDH, Chest CT

\section{Introduction}

The fast-growing outbreak of the 2019 novel coronavirus (COVID-19), which originated from Wuhan in central China, reached multiple continents in merely a month. Cross person-to-person transmission of this new virus can result in severe and fatal respiratory disease like

\footnotetext{
* Correspondence: tangpeipei001@163.com; chencheng@suda.edu.cn ${ }^{\dagger}$ Mei-ying Wu and Lin Yao contributed equally and are regarded as co-first authors.

'Department of Pulmonary, The Fifth People's Hospital of Suzhou, 10 Guangqian Road, Suzhou 215000, China

${ }^{3}$ Department of Respiratory and Critical Medicine, The First Affiliated Hospital of Soochow University, 899 Pinghai Road, Suzhou 215000, China

Full list of author information is available at the end of the article
}

acute respiratory distress syndrome (ARDS) in humans [1]. With the gradual recognition of COVID-19 pneumonia, professional consensus, guidelines and criteria were steadily established with the aim of preventing transmission and facilitating diagnosis and treatment.

Although COVID-19 pneumonia was considered as a low lethal disease, recognition of disease progression was an important decision point concerning intensive therapies [1, 2]. Accordingly, chest CT has been preferentially used as a stable marker of COVID-19 pneumonia, but clinical experiences have revealed the decrease of its availability in critical cases. Therefore, a more sensitive

C C The Author(s). 2020 Open Access This article is licensed under a Creative Commons Attribution 4.0 International License, which permits use, sharing, adaptation, distribution and reproduction in any medium or format, as long as you give appropriate credit to the original author(s) and the source, provide a link to the Creative Commons licence, and indicate if changes were made. The images or other third party material in this article are included in the article's Creative Commons licence, unless indicated otherwise in a credit line to the material. If material is not included in the article's Creative Commons licence and your intended use is not permitted by statutory regulation or exceeds the permitted use, you will need to obtain permission directly from the copyright holder. To view a copy of this licence, visit http://creativecommons.org/licenses/by/4.0/. The Creative Commons Public Domain Dedication waiver (http://creativecommons.org/publicdomain/zero/1.0/) applies to the data made available in this article, unless otherwise stated in a credit line to the data. 
and specific disease-progression marker of COVID-19 pneumonia has been required.

Lactate dehydrogenase (LDH) is an enzyme implicated in the conversion of lactate to pyruvate in the cells of most body tissues and increased following tissue breakdown. Consequently, elevated serum LDH is present in numerous clinical conditions, such as hemolysis, cancer, severe infections and sepsis, liver diseases, hematologic malignancies, and many others. Nowadays, there was much evidence suggesting that the serum LDH levels serve as a non-specific indicator of cellular death in many diseases $[3,4]$. However, the current information about dynamic change of LDH in COVID-19 pneumonia was very still.

Here, we hypothesized that certain LDH change might be correlated to the time course of COVID-19 pneumonia. We therefore measured LDH levels and related them to disease's severity and status. It was aimed to establish serum LDH as a potential marker for monitoring treatment response in COVID-19 pneumonia.

\section{Patients and methods Patients}

All 87 patients were admitted to The Fifth Hospital of Suzhou and diagnosed with COVID-19 pneumonia from Jan 10 to Feb 16, 2020. Diagnosis of COVID-19 infection in patients was made by positive test for viral RNA of respiratory secretions obtained by bronchoalveolar lavage, sputum, nasopharyngeal swab, or oropharyngeal swab. Demographic information, clinical characteristics (included medical history, severity and comorbidities) and chest CT scan results of each patient were obtained from the electronical medical record system of The Fifth hospital of Suzhou. Severity of COVID-19 was defined according to the diagnostic and treatment guideline for COVID-19 pneumonia issued by Chinese National Health Committee (Version 1-6). The study was approved by the Ethics Committee of our Institute of The Fifth People's Hospital of Suzhou (2020-005).

\section{Treatment and evaluation}

Clinical treatment and assessments were carried out by the diagnostic and treatment guideline for COVID-19 pneumonia issued by Chinese National Health Committee (Version 1-6). As multiple pulmonary CT scans provided reliable data, it was preferentially used as a gold standard of disease status.

\section{Serial determinations of LDH levels}

The serum LDH was determined by VITROS $^{\circ}$ dry chemistry analyzer (Johnson, range from 313 to $618 \mathrm{U} / \mathrm{L}$ ) [5, 6]. All operations are performed in strict accordance with the operating instructions. The serum LDH levels were investigated at diagnosis and at routine follow-up visits. The serial value of $\mathrm{LDH}$ was selected around the data of chest CT scan ( $1 \sim+1$ day).

\section{Definition}

The time to LDH normalization referred to the time interval from increased LDH to normalized LDH. This CT image scoring system was an adaptation of a method previously used to describe idiopathic pulmonary fibrosis and severe acute respiratory syndrome (SARS) [7]. CT score was assigned to each lung and each lobe, based on the size of the infected area. The score ranged from 0 to 5 , with score 0 for no infected area, 1 for less than $5 \%, 2$ for $6-25 \%, 3$ for $26-50 \%, 4$ for $51-75 \%$, and 5 for more than $75 \%$. The peak progress on CT (PPC) was defined as the highest score of CT image, remarkable absorption on CT (RAC) was defined as reduced CT image score by $50 \%$ compared to PPC. The time to radiographic absorption (TRA) was established as the time interval from $\mathrm{PPC}$ to time point of beginning reduction in CT image score.

\section{Statistical analysis}

The normality of all data was tested by KolmogorovSmirnov test. The levels of LDH were compared between non-severe patients and severe patients using $t$ test. The values of LDH selected from the data of admission, PPC, and RAC were compared using pairedsamples $\mathrm{T}$ test. The predictive ability of decrease or increase in LDH to corresponding radiographic absorption or progression was evaluated by $\mathrm{X}^{2}$ tests. Receiver operating characteristic (ROC) curves were calculated in order to select the cut-off level of an increase or decrease in serum LDH indicating progress or improvement of adjacent chest scan. The correlation of the time to LDH normalization and the TRA was analyzed by Pearson correlation. All tests were two-sided with a $P$ value of less than 0.05 being considered statistically significant.

\section{Results}

Demographics and clinical characteristics

Among those patients (Table 1), 47 were male and 40 were female. Their age was in the range of 1 to 70 years old, with median age of 44 years old, and $35.6 \%$ (31/87) of them were more than 50 years old. The patients were categorized into 77 non-severe and 10 severe cases on admission. Underlying comorbidity was found in 28 (32.2\%) patients, including hypertension $(6,6.9 \%)$, diabetes $(5,5.7 \%)$, and chronic airway diseases patients $(5$, $5.7 \%)$.

\section{The LDH level at admission}

At admission, the LDH level in all patients was $495.1 \pm$ $28.22 \mathrm{U} / \mathrm{L}$ (range 158-1482 U/L). The LDH level in non- 
Table 1 Baseline characteristics of infected patients

\begin{tabular}{ll}
\hline Baseline characteristics & $\mathrm{n} / \mathrm{value}$ \\
\hline Gender & 47 \\
male & 40 \\
female & 44 \\
Age (years, median) & 6 \\
Smoking history & \\
Underlying conditions & 6 \\
Hypertension & 5 \\
Diabetes & 5 \\
Chronic airway diseases & 2 \\
Chronic kidney diseases & 2 \\
Hepatitis B & 1 \\
Hepatocellular carcinoma & 1 \\
Pregnancy & \\
Clinical severity & \\
Non-severe & 77 \\
Severe & 10 \\
\hline
\end{tabular}

severe patients amounted to $442.0 \pm 17.47 \mathrm{U} / \mathrm{L}$, the higher LDH levels were found in the severe group with a LDH level of $1040.0 \pm 158.3 \mathrm{U} / \mathrm{L}$ (Fig. $1, P<0.01$ ).

\section{Correlation of fluctuation of LDH with radiographic change during hospitalization}

Negative chest findings were revealed in 7 patients (7/ $87,8.1 \%)$, repeated pulmonary CT still showed no abnormalities in these patients. Therefore, these features do not to allow the definition of COVID-19 pneumonia from others. Then, the remaining 80 patients were enrolled in following investigation.

During hospitalization, the majority of enrolling patients exhibited clinical progress. As multiple pulmonary CT scans and serial LDH determination provided reliable data, we investigated the correlation of serum LDH change with clinical status. As shown in Table 2, it was indicated that decrease or increase of LDH was indicative of corresponding radiographic improvement or progression $(P<0.05)$.

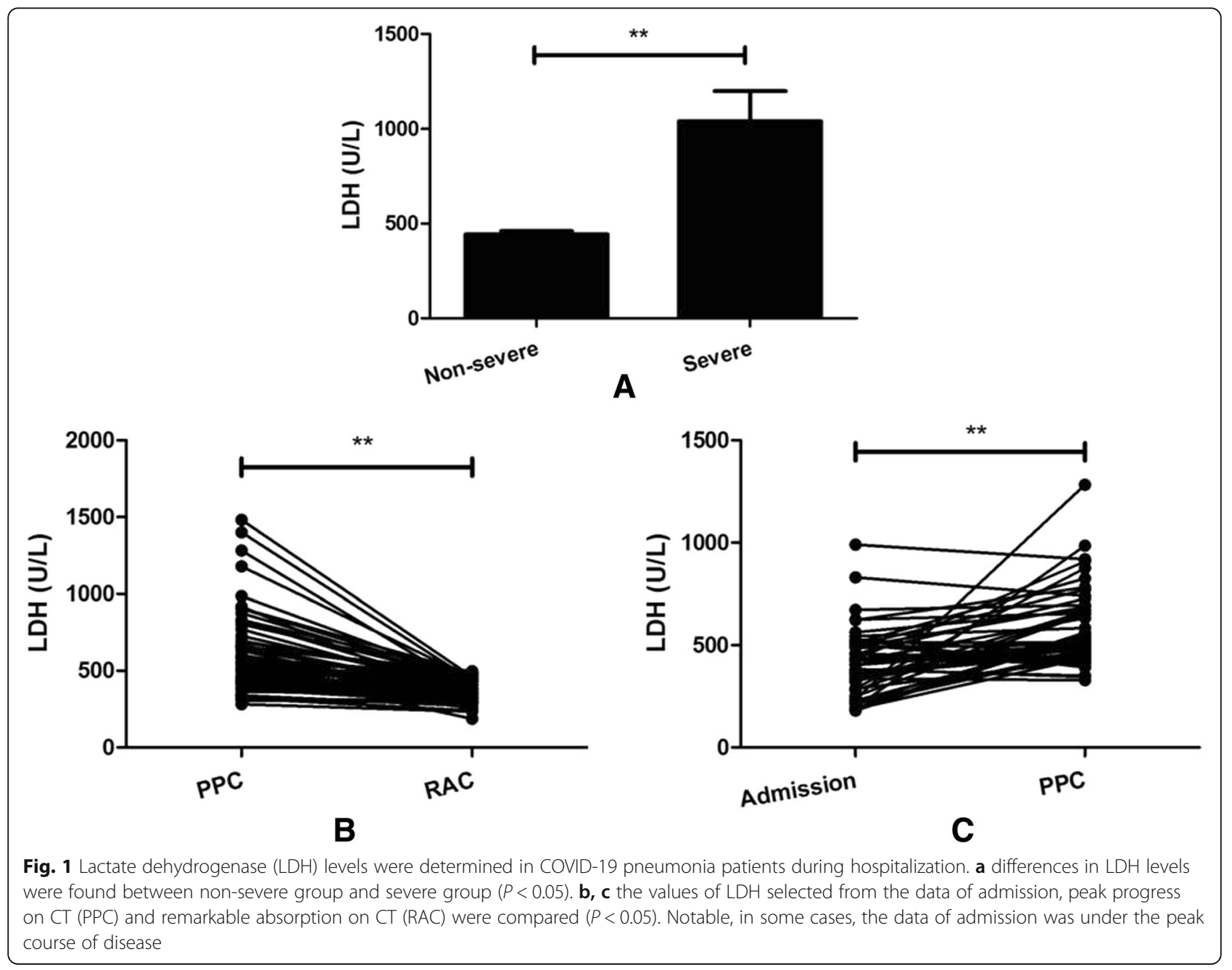


Table 2 Correlation of fluctuation of LDH with radiographic change during hospitalization in COVID-19 pneumonia patients

\begin{tabular}{llll}
\hline $\mathrm{CT}$ image & Progress & Absorption & $P$ value \\
$\mathrm{LDH}$ & & & \\
\hline Increase & 54 & 30 & $<0.01$ \\
Decrease & 22 & 183 & \\
\hline
\end{tabular}

As supported, compared to the initial LDH level $(408.4 \pm 23.77 \mathrm{U} / \mathrm{L})$, the higher LDH levels were found in the following PPC with a level of $584.0 \pm 27.14 \mathrm{U} / \mathrm{L}$ (Fig. $1, P<0.05)$. When compared to the setting of PPC, the lower LDH levels were found in the following RAC $(372.3 \pm 8.25 \mathrm{U} / \mathrm{L}$ vs $578.9 \pm 27.07 \mathrm{U} / \mathrm{L}, P<0.05)$.

\section{LDH normalization and CT image improvement}

Of the 80 patients, 22 were noticed by increased LDH level above normal range (>618 U/L). As shown in Fig. 2, base on the Pearson correlation coefficient, the data showed that the time to LDH normalization $(5.67 \pm 0.55$, days) was positively correlated with time to radiographic absorption (5.57 \pm 0.65 days, $\mathrm{r}=0.53, P<0.05)$.

\section{Predictive value of the LDH level to clinical overcome}

Following, to determine the optimal cut-off level for an increase or decrease in $\mathrm{LDH}$ indicating progress or improvement, ROC curves were calculated. Variations in adjacent LDH levels were computed as a function of the difference around the data of chest CT scan. As shown in Fig. 3, the optimal prognostic "cut-off value of LDH increase" predicting progress of the chest $\mathrm{CT}$ image was found to be $62.50 \mathrm{U} / \mathrm{L}$. Applying the cut-off criterion, the sensitivity for disease progression was found to be $73.1 \%$ and the specificity was found to be $89.3 \%$. The optimal prognostic "cut-off value of LDH decrease" predicting improvement of the chest CT image was found

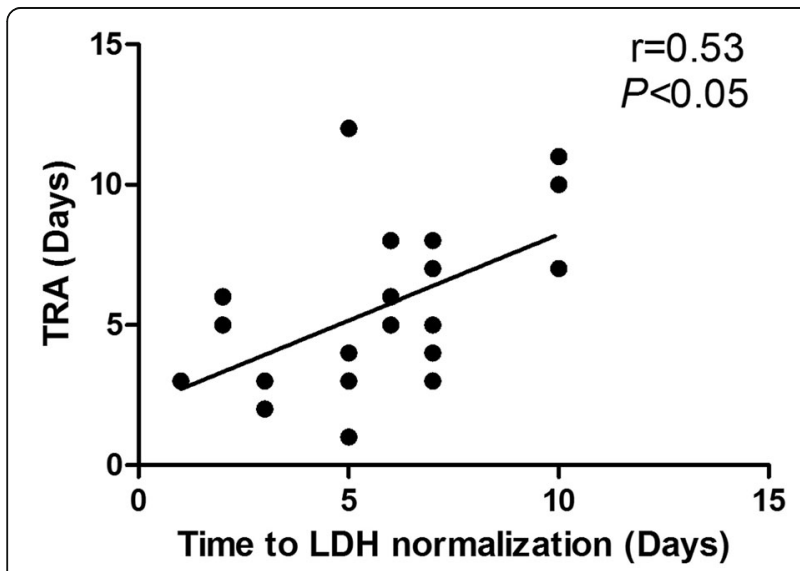

Fig. 2 The correlation of the time to LDH normalization (days) with the time to radiographic absorption (TRA, days) was assessed by Pearson efficient to be $48.5 \mathrm{U} / \mathrm{L}$, its sensitivity and specificity was found to be 67.3 and $56.0 \%$, respectively.

\section{Discussion}

COVID-19 is an emerging viral illness that has rapidly transmitted throughout the world. From the early published literature, it has shown that the disease could induce symptoms including fever, dry cough, dyspnea and fatigue in infected patients $[1,2]$. Clinically, some patients with COVID-19 pneumonia consistently demonstrated progress during the course of hospitalization, recognition of disease progression was an important decision point concerning intensive therapies.

The dynamic profile of laboratory findings has been tracked in patients with COVID-19 pneumonia. In the nonsurvivors, the neutrophil count, D-dimer, blood urea, and creatinine levels continued to increase, and the lymphocyte counts continued to decrease until death occurred. The risk factors indicated the importance of taking into account the disease severity, laboratory findings, chest imaging findings in practice $[2,8]$. Under the circumstances, studies of the association between objective disease status and the laboratory findings may produce more interesting findings.

LDH can be released during tissue damage and is involved in various pathophysiological processes and serve as a non-specific indicator of cellular death in many diseases. A number of previous studies have shown that an elevated serum $\mathrm{LDH}$ is associated with a poor prognosis in malignancy [9-11]. In most scoring systems presented so far, prognostic variables including LDH were used as static variables determined at the time of diagnosis. The dynamics of the disease, however, may also be of great importance, especially when considering 'decision points' in treatment algorithms such as stem-cell transplantation [12].

For this reason, there was an urgent need to verify and update dynamic variables including $\mathrm{LDH}$ as the number of COVID-19 pneumonia accumulates. In the present study, serum LDH was validated for its potential usefulness as markers for evaluating clinical severity and monitoring treatment response in COVID-19 pneumonia. It was demonstrated that increase or decrease of $\mathrm{LDH}$ was indicative of radiographic progress or improvement. An increase in LDH by $62.5 \mathrm{U} / \mathrm{L}$ has an acceptable sensitivity and high specificity for a significantly higher probability of disease progression, when chest CT scan was employed to confirm the prediction. In support, during the whole observation period, normalization of serum LDH titer was consistently accurate in predicting treatment success in the patients.

It was known that kinds of disorders can raise LDH levels, such as infectious disease, heart failure, hypothyroidism and cancer. The inflammatory responses 


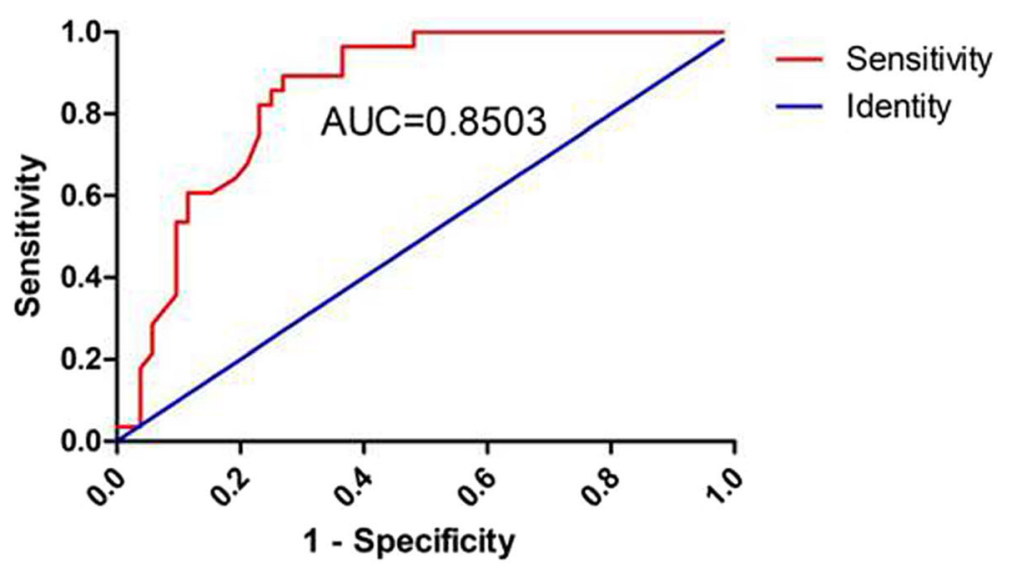

A

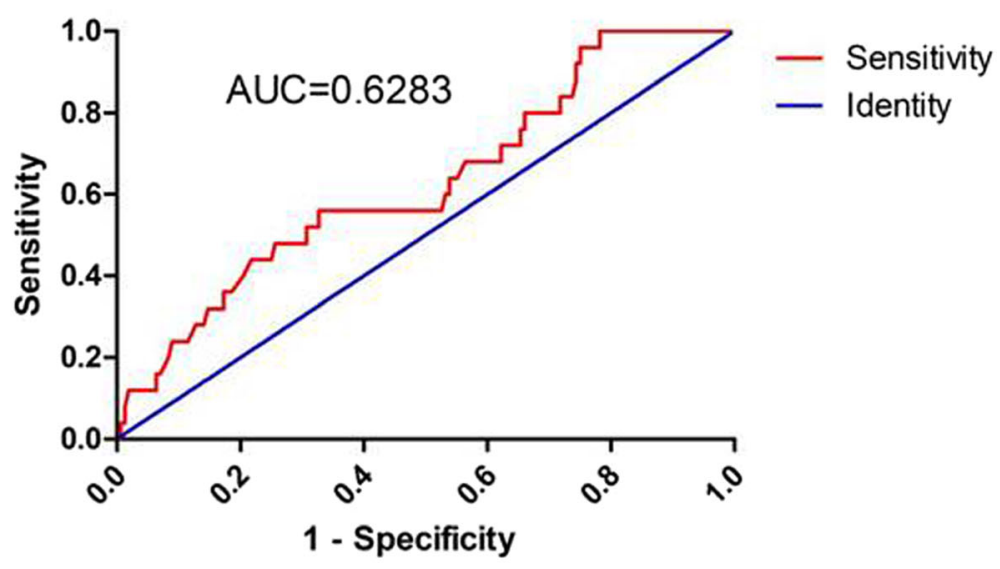

B

Fig. 3 Predictive value of the LDH level to clinical overcome. a the optimal prognostic "cut-off value of LDH increase" predicting progress of the chest $C T$ image was found to be $62.50 \mathrm{U} / \mathrm{L}$, this criterion for sensitivity and specificity was found to be 73.1 and $89.3 \%$ respectively $(A \cup C=0.8503$, $P<0.01$ ). b The optimal prognostic "cut-off value of $L D H$ decrease" predicting improvement of the chest $C T$ image was found to be $48.50 \mathrm{U} / \mathrm{L}$, the sensitivity and specificity was found to be 67.3 and $56.0 \%$ respectively $(A \cup C=0.6283 P=0.04)$

reflected the nonspecific responses to hypoxia, tissue injury, and necrosis, indicating a correlation between infectious cells, immune system and inflammatory response $[13,14]$. Neutrophilia may be related to cytokine storm induced by virus invasion, coagulation activation could have been related to sustained inflammatory response [15]. In this study, complications of COVID-19 pneumonia included respiratory failure and liver injury. It is believed that the complication was signs of progression of disease, in turn produced influence on disease.

There are several limitations to our study. Firstly, almost all patients may have received medical intervention (antimicrobial therapy, fluid administration, mechanical ventilation, or steroid therapy), which may affect serum LDH titer. In addition, there may have been a selection bias in one medical institution. Moreover, a decrease in
LDH by cut-off value has a poor sensitivity and specificity to predicting of image improvement, which might due to secondary organ dysfunction in late-term of diseases, not the direct the effect of pulmonary abnormality.

Taken together, our data suggested that LDH is a potentially useful follow-up parameter in COVID-19 pneumonia, which might assist in recognition of disease progression and thus help in risk stratification and early intervention.

\section{Abbreviations}

ARDS: Acute respiratory distress syndrome; COVID-19: 2019 Novel Coronavirus; LDH: Lactate dehydrogenase; PPC: Peak progress on CT; RAC: Remarkable absorption on CT; ROC: Receiver operating characteristic

\section{Acknowledgements}

We thank the patients, the nurses and clinical staff who are providing care for the patients, and staff at the local and state health departments. 


\section{Authors' contributions}

CC and TPJ participated in the conception, the design, coordination of the study, and manuscript preparing. ZXY and WXF conceived of the study, and participated in its design. WY participated in data collecting. $Y L$ and WMY participated in the design and coordination of the study. The author(s) read and approved the final manuscript.

\section{Funding}

This work was supported by the Jiangsu Youth Medical Talents Project (QNRC2016226) and Jiangsu Provincial Health Commission Scientific Research Project (LGY2019014, LGY2019083). The funders had no role in the study design, data collection and analysis, decision to publish, or preparation of the manuscript.

\section{Availability of data and materials}

All data generated during this study are included in this published article.

\section{Ethics approval and consent to participate}

The study was approved by the Ethics Committee of our Institute of The Fifth People's Hospital of Suzhou (2020-005).

\section{Consent for publication}

In this retrospective small-scale study, written informed consent from the patients were waived, which was approved by the Ethics Committee of our Institute of The Fifth People's Hospital of Suzhou (2020-005).

\section{Competing interests}

The authors declare that they have no competing interests.

\section{Author details}

'Department of Pulmonary, The Fifth People's Hospital of Suzhou, 10 Guangqian Road, Suzhou 215000, China. ${ }^{2}$ Department of Pulmonary, The Affiliated Infectious Hospital of Soochow University, 10 Guangqian Road, Suzhou 215000, China. ${ }^{3}$ Department of Respiratory and Critical Medicine, The First Affiliated Hospital of Soochow University, 899 Pinghai Road, Suzhou 215000, China. ${ }^{4}$ Institute of Respiratory Diseases, Soochow University, 708 Renmin Road, Suzhou 215006, China.

Received: 4 March 2020 Accepted: 17 June 2020

Published online: 06 July 2020

\section{References}

1. Chen N, Zhou M, Dong X, Qu J, Gong F, Han Y, et al. Epidemiological and clinical characteristics of 99 cases of 2019 novel coronavirus pneumonia in Wuhan, China: a descriptive study. Lancet. 2020;395(10223):507-13.

2. Wang D, Hu B, Hu C, Zhu F, Liu X, Zhang J, et al. Clinical characteristics of 138 hospitalized patients with 2019 novel coronavirus-infected pneumonia in Wuhan, China. JAMA. 2020:323(11):1061-9.

3. Kolev Y, Uetake H, Takagi Y, Sugihara K. Lactate dehydrogenase-5 (LDH-5) expression in human gastric cancer: association with hypoxia-inducible factor (HIF-1alpha) pathway, angiogenic factors production and poor prognosis. Ann Surg Oncol. 2008;15(8):2336-44.

4. Uchide N, Ohyama K, Bessho T, Toyoda H. Lactate dehydrogenase leakage as a marker for apoptotic cell degradation induced by influenza virus infection in human fetal membrane cells. Intervirology. 2009:52(3):164-73.

5. Adams A, Straseski JA, Lehman CM, Pearson LN. Peritoneal and pleural fluid chemistry measurements performed on three chemistry platforms. Lab Med. 2019;50(2):145-9.

6. Lokesh KS, Deep D, Neera S, Bhaskar T. Comparisons of metabolite profile from paired serum and ethylenediaminetetraacetic acid-plasma samples using dry chemistry technology: an emergency department perspective. J Lab Physicians. 2018;10(3):346-50.

7. Ooi GC, Khong PL, Muller NL, Yiu WC, Zhou L, Ho JCM, et al. Severe acute respiratory syndrome: temporal lung changes at thin-section $C T$ in 30 patients. Radiology. 2004;230(3):839-44.

8. Pan F, Ye T, Sun P, Gui S, Liang B, Li L, et al. Time course of lung changes on chest CT during recovery from 2019 novel coronavirus (COVID-19) pneumonia. Radiology. 2020;295(3):715-21.

9. up J, Kim HS, Lee HE, Yang HK, Kim WH, et al. High lactate dehydrogenase 5 expression correlates with high tumoral and stromal vascular endothelial growth factor expression in gastric cancer. Pathobiology. 2014;81:78-85.
10. Wimazal F, Sperr WR, Kundi M, Vales A, Fonatsch C, Thalhammer-Scherrer R, et al. Prognostic significance of serial determinations of lactate dehydrogenase (LDH) in the follow-up of patients with myelodysplastic syndromes. Ann Oncol. 2008;19(5):970-6.

11. Scartozzi M, Giampieri R, Maccaroni E, Del Prete M, Faloppi L, Bianconi M, et al. Pre-treatment lactate dehydrogenase levels as predictor of efficacy of first-line bevacizumab-based therapy in metastatic colorectal cancer patients. Br J Cancer. 2012;106(5):799-804.

12. Malcovati L, Germing U, Kuendgen A, Della Porta MG, Pascutto C, Invernizzi $R$, et al. Time-dependent prognostic scoring system for predicting survival and leukemic evolution in myelodysplastic syndromes. J Clin Oncol. 2007; 25(23):3503-10.

13. Jovanović S, Du Q, Sukhodub A, Jovanović A. M-LDH physically associated with sarcolemmal K ATP channels mediates cytoprotection in heart embryonic H9C2 cells. Int J Biochem Cell Biol. 2009;41(11):2295-301.

14. Li G, Fan Y, Lai Y, et al. Coronavirus infections and immune responses. J Med Virol. 2020;92(4):424-32.

15. Channappanavar R, Perlman S. Pathogenic human coronavirus infections: causes and consequences of cytokine storm and immunopathology. Semin Immunopathol. 2017;39:529-39.

\section{Publisher's Note}

Springer Nature remains neutral with regard to jurisdictional claims in published maps and institutional affiliations.

\section{Ready to submit your research? Choose BMC and benefit from:}

- fast, convenient online submission

- thorough peer review by experienced researchers in your field

- rapid publication on acceptance

- support for research data, including large and complex data types

- gold Open Access which fosters wider collaboration and increased citations

- maximum visibility for your research: over $100 \mathrm{M}$ website views per year

At $\mathrm{BMC}$, research is always in progress.

Learn more biomedcentral.com/submissions 